\title{
Infiltrating Bladder Urothelial Carcinoma
}

National Cancer Institute

\section{Source}

National Cancer Institute. Infiltrating Bladder Urothelial Carcinoma. NCI Thesaurus. Code C27885.

An invasive transitional cell carcinoma that arises from the urinary bladder urothelium. 